OUTROS

TEMAS 


\title{
OS CIDADÃOS-PROFESSORES E A FORMAÇÃO PARAA CIDADANIA NA CONSTRUÇÃO DE ESCOLAS DEMOCRÁTICAS
}

Arthur Breno Stürmer

Liliana Soares Ferreira

\begin{abstract}
Resumo
O presente artigo discute a formação para a cidadania em escolas públicas estaduais de Santa Catarina, com foco na atuação dos cidadãosprofessores e nas Instâncias de Gestão Escolar Democrática (IGEDs). Trata dos pressupostos históricos e legais da escola democrática, aborda as condições de formação dos cidadãos e até chegar ao papel dos cidadãos-professores diante da construção de escolas democráticas. Os dados procedem de pesquisa desenvolvida no Curso de Especialização em Gestão Educacional da Universidade Federal de Santa Maria/UAB. A partir do questionamento de dezessete professores, salienta-se que os cidadãos-professores pouco participam das principais IGEDs - Conselho Escolar e a Associação de Pais e Professores -, as quais não funcionam como núcleos de formação para a cidadania. Logo, a experiência de construção de escolas democráticas necessita de maior empenho e estímulo à participação direta, seja dos professores, seja da comunidade como um todo.
\end{abstract}

Palavras-chave: gestão escolar, democracia, cidadania.

\section{CITIZENS AND TEACHER-TRAINING FOR CITIZENSHIP IN BUILDING SCHOOLS FOR DEMOCRATIC}

\begin{abstract}
The present article argues the formation for the citizenship in state public schools of Santa Catarina, with focus in the performance of the citizen-professors and the Instances of Democratic School Management (IGEDs). It deals with the historical estimated ones and legal of the democratic school, it approaches the conditions of formation of the citizens and until arriving ahead at the paper of the citizen-professors of the construction of democratic schools. The data proceed from research developed in the Course of Specialization in Educational Management of the Universidade Federal de Santa Maria/UAB. From the questioning of dezessete professors, salient that the main citizenprofessors little participate of the IGEDs - School Advice and the Association of Parents and Professors -, which do not function as nuclei of formation for the citizenship. Soon, the experience of construction of democratic schools needs bigger persistence and stimulaton to the direct participation, either of the professors, either of the community as a whole.
\end{abstract}

Keywords: school management, democracy, citizenship.

REGAE, Santa Maria, v. 1, n. 2, jul./dez. 2009 


\section{A. B. Stürmer; L. Soares Ferreira}

\section{Introdução}

É que a democracia, como qualquer sonho, não se faz com palavras desencarnadas, mas com reflexão e prática.

Paulo Freire

As perspectivas de construção de uma escola verdadeiramente democrática passa pelo trabalho docente. As escolas públicas de Educação Básica, e nelas os professores, são a força motriz de um processo inconcluso que supõe grande empenho e força de vontade docente. Em última instância, uma sociedade democrática depende do trabalho pedagógico constante realizado pelos professores em suas escolas, majoritariamente as da rede estadual de ensino.

O termo "escolas democráticas" será aqui utilizado para designar aquelas escolas que buscam cumprir seu dever de formar para a cidadania, seja pelo exemplo pessoal de seus servidores, através de métodos de ensino próprios, seja pela organização e funcionamento da escola, no caso de se adotarem mecanismos de participação específicos para desenvolvê-la.

Atualmente, as escolas públicas comportam espaços-tempos pedagógicos capazes de oferecer condições para o desenvolvimento de uma mentalidade democrática, aberta ao debate, à negociação de regras e constituição conjunta de projetos e propostas pedagógicas voltados à formação para a cidadania. Tal aspecto, notadamente relacionado à gestão escolar, é um dos fundamentos que sustentam as escolas democráticas.

Os espaços-tempos mais adequados ao desenvolvimento da democracia na escola são as Instâncias de Gestão Escolar Democrática (IGEDs). Presentes nas escolas públicas, elas são um meio viável para iniciar ou dar continuidade aos processos de abertura democrática da escola à comunidade local e escolar, todavia focalizando seus esforços, por exemplo, não na arrecadação para a caixa escolar ou simplesmente referendando decisões de outras instâncias administrativas, mas assumindo a função de promover a cidadania dos estudantes. Nas IGEDs, pode-se capacitar os estudantes para o entendimento do jogo político-democrático da sociedade, baseando-se no diálogo, no qual a peça-chave é a compreensão mútua e o convívio com diferentes versões e visões de mundo.

Para que as IGEDs adquiram tais características, há a necessidade inicial de conduzi-las sob orientação dos professores, a fim de que estejam a serviço da formação para a cidadania, induzindo o progresso de uma ordem escolar tanto menos autoritária quanto mais comprometida, pri- 
meiro, com o desenvolvimento pleno do ser humano e, segundo, com o seu preparo para o exercício integral da cidadania. Agindo conforme estes dois parâmetros, os docentes, no papel de cidadãos-professores, sujeitos da formação político-cidadã, cumprem a tarefa de articular uma nova concepção de escola pública, que guarde a responsabilidade de instaurar o direito à liberdade, nos termos do art. 16, incisos I, V e VI, da Lei no 8.069/90, os quais asseguram as liberdades de opinião e expressão e de participação nas vidas comunitária e política às crianças e aos adolescentes.

O presente artigo discute a formação para a cidadania, na qual o cidadão-professor se utiliza das IGEDs para realizar a formação para a cidadania e valorizar o aspecto político-pedagógico de sua prática docente, tendo como plano de fundo a escola pública catarinense e seus instrumentos (espaços-tempos) de gestão democrática - as IGEDs. Após apresentar o objeto/campo de estudo e as opções metodológicas, o artigo divide-se em três grandes partes: a primeira, tratando dos pressupostos históricos e legais da democracia na escola; o segundo abordando as condições que a escola pública apresenta para a formação de cidadãos, em termos de estrutura de gestão e incentivo à participação; e a terceira parte sobre a função dos cidadãos-professores frente ao contexto das escolas democráticas em construção, quando se discutirão resultados de pesquisa sobre o assunto.

A temática é desenvolvida a partir dos resultados obtidos em pesquisa na área de gestão educacional, dentro do Programa de Pós-Graduação da Universidade Federal de Santa Maria e serve de elemento de reflexão sobre a atuação do profissional docente na escola, tendo como base os objetivos e finalidades da Educação Básica.

As principais teses defendidas referem-se ao caráter paradigmático das atuais formas de administração da educação, à organicidade entre orientação docente, colegiados escolares e democracia na escola, e, implicitamente, a tese de que a construção de escolas democráticas é fruto do esforço coletivo capitaneado pelos cidadãos-professores, dos quais depende a sequência deste processo.

\section{A constituição do objeto/campo de estudo}

As escolas da rede pública estadual de ensino, em Santa Catarina, vivenciam um dilema em suas formas de "administração" da educação. De um mesmo lado, tem-se a administração gerencial no âmbito do sistema estadual de educação coadunando-se com o estímulo à gestão democrática 


\section{A. B. Stürmer; L. Soares Ferreira}

nas unidades escolares, em acordo com o novo paradigma (participativo) de gestão. Nestas últimas, os reflexos vêm se fazendo sentir na formação para a cidadania, que, através dos colegiados escolares, abrem-se perspectivas de constituição de uma escola democrática em novas bases, alterando as relações de trabalho, o grau de participação de professores, estudantes e pais na gestão das escolas, e, consequentemente, da qualidade da educação escolar.

Adotando as escolas da rede pública estadual de ensino como campo ou domínio de pesquisa, foram selecionadas duas Gerências Regionais de Educação (GEREDs) - $6^{\mathrm{a}}$ e $33^{\mathrm{a}}-$, que se situam na Região (geográfica) Oeste de Santa Catarina, para aplicar o instrumento de pesquisa com professores, em função da proximidade entre as suas respectivas unidades escolares e o local de atuação profissional do pesquisador.

\section{As opções metodológicas}

Haja vista a natureza da temática em questão, geralmente envolta em disputas político-ideológicas, somada ao intuito de se obter resultados fidedignos e de contribuir com o aperfeiçoamento do trabalho pedagógico dos professores. Assim, o público-alvo da pesquisa esteve circunscrito aos professores de variadas unidades escolares que, em caráter voluntário, se dispuseram a responder um questionário composto de 11 questões abertas em presença do pesquisador, na maioria dos casos.

O questionário esteve centrado nas instâncias colegiadas, tomadas como lócus do debate democrático e possível ponto de partida para a formação do cidadão e constituição da democracia na escola. Focalizou, dentre outros, o Projeto Político-Pedagógico (PPP), considerado aqui um instrumento-guia dos rumos da unidade escolar devido ao caráter coletivo do seu processo de elaboração, capaz de estimular a participação de toda a comunidade escolar.

Com esta proposta de pesquisa, foram investigados os aspectos do meio (escolar) no qual o pesquisador está inserido e onde desenvolve sua prática profissional. Por isso, adota a posição de quem pretende resolver ou ao menos contribuir para o esclarecimento da situação social que forneceu seu objeto de estudo. Foi utilizada a pesquisa qualitativa, próxima da pesquisa-ação, a fim de "estudar dinamicamente os problemas, decisões, ações, negociações, conflitos e tomadas de consciência que ocorrem entre os agentes durante o processo de transformação da situação." (THIOLLENT, 
1998, p. 19).

Procura-se esclarecer a estrutura de gestão das unidades escolares para que, através do desenvolvimento das crenças dos trabalhadores da educação, se possa contribuir com a construção de uma escola democrática. Trata-se de "desenvolver a consciência da coletividade nos planos político ou cultural a respeito dos problemas importantes que [a escola] enfrenta" na sua gestão. Isso para "tornar mais evidente aos olhos dos interessados a natureza e a complexidade dos problemas considerados" (Id. p. 18).

\section{Fundamentos para a ação docente em cidadania}

\subsection{Histórico de formação do contexto escolar democrático}

As discussões sobre a construção de uma escola democrática - e cidadã - na rede pública catarinense de ensino datam da década de 1980, quando movimentos sociais de âmbito nacional, reivindicando o fim da ditadura, repercutiram em Santa Catarina. Surgidos ainda dentro dos parâmetros de uma sociedade fechada (FREIRE, 1983)1, esses movimentos viam na democracia a possibilidade de reaver a todos os cidadãos direitos políticos básicos, como a livre organização partidária e sindical, além da liberdade de opinião e expressão.

Iniciou-se um ciclo de transformação da sociedade autoritária em democrática, no qual as escolas receberam atenção especial. Em primeiro lugar, por serem um canal de ascensão das massas, que exigiam mais educação, uma vez que esta lhes abriria perspectivas de melhoria de suas condições socioeconômicas. Segundo, por serem espaços públicos de formação de um novo cidadão para uma Nova República, demandando a instrumentalização das massas para a participação no processo político.

Estendendo-se a todos os setores da sociedade, a democracia chegou à seara da educação catarinense por meio do Plano Estadual de Educação (1985-1988), intitulado Democratização da educação: a opção dos catarinenses. Esse documento afetou principalmente as escolas estaduais, imprimindo-lhes os rumos de um processo democrático que, por definição, está inconcluso e depende do desempenho dos colegiados escolares. 


\subsection{Bases legais para formar o novo cidadão}

Alguns documentos legais sustentam a busca permanente por mecanismos de participação democrática na educação escolar, dentre os quais aqueles que incidem diretamente sobre o regime de gestão escolar. Seis documentos merecem destaque, por incidirem sobre o processo de construção de escolas democráticas. Podem-se citar, em ordem de criação, a Constituição Federal, o Estatuto da Criança e do Adolescente, a Lei de Diretrizes da Educação Nacional, a Lei do Sistema Estadual de Educação, e, mais recentemente, o Projeto de Lei do Senado $n^{\circ} 344 / 07$ e respectivo Parecer da CEC do Senado $n^{0}$ 1.269/o8.

A Constituição Federal de 1988, conhecida como "a Constituição Democrática”, traz a gestão democrática como um princípio do ensino e o exercício da cidadania como um fim da educação. No texto constitucional, prevalece a noção de que tanto a "gestão democrática do ensino público" quanto o "preparo para o exercício da cidadania" pode acontecer dentro da própria instituição escolar. Não aponta, entretanto, qualquer forma ou procedimentos. A cidadania, assim, poderia ser ensinada na sala de aula, como tema transversal, ao passo que seria exercida, praticada, em espaços-tempos como os colegiados, que acompanham o modelo de gestão escolar dito democrático.

A Lei do Sistema Estadual de Educação, ou Lei Complementar $n^{\circ}$ 170/.98, reforça a gestão democrática do ensino como princípio a que obedece a "educação escolar", embora a restrinja à educação pública, em capítulo especial. Nele, a gestão democrática da educação pública figura "como ação coletiva e prática político-filosófica”, sem se vincular necessariamente à formação para a cidadania, porém ao "planejamento, formulação, implementação e avaliação das políticas educacionais" (art. 18). Por outro lado, conforme o art. 19, cada instituição de Educação Básica pública terá o Conselho Deliberativo Escolar como instrumento que assegura a gestão democrática e do qual participem representantes da respectiva comunidade escolar, local e regional.

O Estatuto da Criança e do Adolescente (ECA), Lei no 8.069/9o, menciona o princípio democrático ao "outro" da relação pedagógica - o estudante -, que tem assegurado o direito de se organizar e participar de entidades estudantis (art. 53, inciso IV)2, bem como seus pais ou responsáveis participarem da definição das propostas educacionais (art. 53, Pará- 
grafo único). O ECA aplica o referido princípio de maneira diversa da Lei de Diretrizes da Educação Nacional, quando concede à criança e ao adolescente o "direito de ser respeitado por seus educadores" (art. 53, inciso II) e lhes confere o "direito de contestar critérios avaliativos, podendo recorrer às instâncias escolares superiores" (art. 53, inciso III).

Percorrendo o texto da Lei de Diretrizes da Educação Nacional (LDBEN), Lei no 9.394/96, percebe-se que o princípio da gestão democrática prevalece sobre quaisquer ingerências ou imposições; antes se direciona a autonomia das estruturas pedagógico-administrativas e financeiras das instituições. $\mathrm{O}$ art. 14 desta lei, por exemplo, prevê a participação dos "profissionais da educação" na elaboração do projeto pedagógico da escola e das "comunidades escolar e local" nos conselhos escolares, instituindo o direito ao exercício da cidadania docente na escola, em um dos processos mais importantes dos estabelecimentos públicos de ensino.

Em apreciação do Projeto de Lei do Senado, PLS n ${ }^{0} 344 / 07$, que institui a eleição direta para diretores de escolas públicas, a relatora da Comissão de Educação, Cultura e Esporte afirma que a eleição, da qual participam professores, funcionários, estudantes e pais é um ato pedagógico com repercussão "na formação dos estudantes e no processo de crescimento coletivo da comunidade escolar" e decorre do princípio da gestão democrática, consagrado na Constituição Federal e na LDB. (BRASIL, 2008).

Com esse novo aporte jurídico-educacional, a educação escolar exerce impactos significativos nas formas de gestão, enquanto a educação escolar básica consolida-se como instituição destinada a promover a cidadania, requerendo para isso uma reestruturação administrativa, a qual vem levando as escolas a se adequarem ao paradigma emergente, tal qual descrito a seguir.

\section{A formação cidadã na escola pública}

A participação pertence à própria natureza do ato pedagógico. Moacir Gadotti

\subsection{Gestão: um conceito em elaboração dentro da escola}

As limitações do modelo estático de escola e de direção cederam lugar a um modelo dinâmico, que trouxe a descentralização, a democratização da gestão escolar e a necessidade de se construir a autonomia da escola. 
Essa mudança de paradigma é marcada por uma forte tendência à adoção de concepções e práticas interativas, participativas e democráticas, caracterizadas por movimentos dinâmicos e globais, com os quais, para determinar as características de produtos e serviços, interagem dirigentes, funcionários e "clientes" ou "usuários", estabelecendo alianças, redes e parcerias, na busca de soluções de problemas e alargamento de horizontes. (LÜCK, 2000, p. 12).

Nas escolas, a mudança quanto à gestão gerou a revalorização de modalidades colegiadas de "administração", que estimularam, em diferentes graus, a participação em âmbito escolar, fazendo reativar os Conselhos Escolares, reorientando a atuação das Associações de Pais e Professores e facilitando a organização estudantil. Assim, visava-se à adaptação da escola a este contexto em mudança a partir de instrumentos que já integravam sua estrutura "administrativa".

O conceito de gestão superou o de administração devido a uma mudança na visão de mundo e no modo de as pessoas perceberem e reagirem em relação à realidade; orienta-se pelos princípios democráticos e caracteriza-se por dar relevo à participação nas decisões sobre o próprio trabalho. Ressalte-se: uma participação mais responsável da sociedade civil e da comunidade escolar nos vários níveis e âmbitos das decisões necessárias à efetiva democratização do processo de gestão educacional mediante compromisso coletivo com resultados concretos e significativos (LÜCK, 2007).

A gestão constitui, necessariamente, em uma ação conjunta, um trabalho coletivo; quer dizer, participativo: "constitui ação conjunta de trabalho participativo em equipe" (Id., p. 43). A nova lógica "administrativa" supõe uma equipe de gestão, na qual a direção, professores e comunidade local participam, decidem e fazem interagir as dimensões política e pedagógica da educação. Para é preciso optar pelos instrumentos adequados. É justamente a essas demandas da sociedade democrática que as Instâncias de Gestão Escolar Democrática (IGEDs) podem responder.

As tentativas de estabelecer uma gestão democrática na Educação Básica completaram duas décadas. Após intenso debate, introduziram-se eleições para representantes discentes na escola e, em número insignificante, para representantes docentes, mas, longe se limitar ao mecanismo do voto, a gestão democrática implica na participação direta. Isso quer dizer: privilegia a experiência com o trabalho coletivo e/nas IGEDs, identificadas pelos Conselhos Deliberativos Escolares, as Associações de Pais e Professores e os Grêmios Estudantis, na rede estadual de ensino de 
Santa Catarina.

Com as IGEDs, a escola reverte o núcleo de gestão centralizada em uma equipe de gestão, que, compartilhando poder e despertando a participação, amplia o círculo de ação aos coordenadores administrativo, pedagógico e outros, bem como convoca todos a participarem diretamente da gestão escolar, na modalidade colegiada. Aos professores, em especial, fica reservada a tarefa de induzir seus estudantes a integrarem-se às IGEDs, na perspectiva da formá-los para a cidadania em um espaço que deve ser amplamente democrático.

A participação é elemento fundamental para o preparo à cidadania e um pressuposto importante para se avançar na gestão democrática. Ela não significa apenas a integração entre da família e comunidade com a escola, nem tampouco a simples colaboração efetuada pelos pais, mas um mecanismo de representação e participação política (APP-SINDICATO, 2007).

Por certo que a participação assume algumas formas distorcidas na escola, por meio de práticas as mais diversas, mas convém recordar que é na escola que essas falhas devem ser corrigidas, atentando-se, principalmente, aos níveis de participação praticados, a fim de se verificar a autenticidade da participação.

Gandin (2001) visualiza três níveis de participação, enfatizando a participação da comunidade na escola:

$1^{\circ}$ ) Nível de colaboração: expressa-se pelo apoio à realização de projetos definidos e implantados pela "autoridade" (diretor). Nesse nível, a comunidade é chamada a fazer festas, contribuir financeiramente e receber informações;

$2^{\circ}$ ) Nível de decisão: realizada ao se decidir, por exemplo, sobre pontos determinados quando da escolha entre duas ou três alternativas indicadas de antemão pelo dirigente da escola, ou seja, a decisão é controlada pelos "chefes", seja por meio do objeto de decisão, seja pelas alternativas propostas;

$3^{\circ}$ ) Nível de construção em conjunto: implica a entrega, à comunidade, das decisões específicas e mesmo dos rumos que se devem imprimir à escola; valoriza-se a diversidade de saberes e faz de cada pessoa a construtora de um todo.

Os dois primeiros níveis estão em uma linha conservadora e não são compatíveis com a formação cidadã e não podem ser considerados como exemplos de gestão escolar democrática, pois há uma nítida separação en- 


\section{A. B. Stürmer; L. Soares Ferreira}

tre o trabalho intelectual - teórico, de concepção - e o trabalho manual, prático - como no caso de simples escolha ou votação. Em outra palavras, a comunidade não participa propriamente da gestão, visto que não acompanha todo o processo, ficando alienada dos debates em torno das questões anunciadas ou dos problemas cruciais da escola. Acaba sendo, portanto, colocada na periferia desse processo.

Por outro lado, o terceiro nível de participação, cujo maior destaque pertence à prática do planejamento participativo, tem se mostrado eficaz para firmar a participação real, cidadã, da comunidade na gestão da escola; está mais próxima da ruptura com as estruturas administrativas e pedagógicas da escola que de sua conservação. A construção em conjunto assemelha-se à participação dita "engajada".

Lück (2006) corrobora a ideia de que o nível mais pleno de participação é a participação como engajamento3, que equivale à presença física, expressão do pensamento, decisão, com base em análises compartilhadas, dentre outras características, além do envolvimento dinâmico nos processos sociais.

\subsection{Autoridade e responsabilidade do cidadãos-professores}

A participação na gestão escolar, como construção em conjunto, especialmente do ponto de vista político, tem sido interpretada sob duas óticas distintas e pelo viés de classe. Governantes e elites defendem-na porque a participação na escola também corresponde à delegação de tarefas ou desconcentração das mesmas: o que parece uma inovação, na verdade, é uma concessão apresentada como conquista popular e altera muito pouco a rígida divisão (social) do trabalho educacional (inclusive aquele realizado pela comunidade), que é nitidamente marcado pela separação entre concepção/elaboração de propostas, de um lado, e execução, de outro.

As classes populares, porquanto socialmente excluídas, vislumbram na gestão democrática, participativa e cidadã uma forma de se apropriar dos avanços de uma sociedade dita democrática. São duas visões diferentes que sinalizam para a dubiedade do processo de abertura da escola à participação. Urge então avaliar o grau de participação dos atores envolvidos no processo. Há partilha da autoridade? Direção, colegiados e autonomia interagem entre si?

O compartilhamento da autoridade, logo do poder decisório e da 
gestão, aponta para uma democracia de alta intensidade, em que as ações coletivas têm espaço e a participação é bem-vinda, sobrepujando as decisões centralizadas e distantes do interesse geral da comunidade escolar (democracia de baixa intensidade)4.

Gutierrez e Catani (2000) ressalvam que a transferência de autoridade e responsabilidade pela gestão para quem está envolvido diretamente no trabalho "é uma prática democrática e socialmente justa" (Ibid., p. 63), exceto se houver incentivo a ações corporativas ou desobrigação do Estado para com a população.

Os professores, conforme Marques (2003, p. 110), são responsáveis, na condição de educadores, "pela direção geral dos processos da educação como tarefa colegiada". São peças fundamentais na constituição de uma gestão democrática na escola, na qual lhes caiba maior autoridade para gerir seu trabalho, fazer proposições baseadas no que dispõe o Projeto Político-Pedagógico (PPP) da escola e proceder à valorização das IGEDs. Deste modo, a responsabilidade dos cidadãos-professores recai não apenas sobre o trabalho de sala de aula, mas sobre um tipo de formação paralela, em que sua autoridade deve ser preservada reconhecida e respeitada.

\subsection{Participação reduzida e obstáculos à gestão democrática}

A participação, em uma gestão escolar que se pretenda democrática, geralmente apresentará as seguintes consequências: a melhor organização da escola e, por extensão, da sociedade civil, assim como o maior envolvimento político, cujo exercício encontrará obstáculos inerentes ao modelo de democracia hegemônico na sociedade brasileira - o modelo (neo)liberal -, que, aliás, não é imutável, dado que a sociedade é dinâmica, embora esteja condicionada por um longo passado histórico. Passado que legou uma cultura de participação reduzida nas questões sociais e políticas, resultado de uma história colonial, imperial, de governos populistas, uns ditatoriais, e que se afinou com as atuais investidas dos discursos e políticas neoliberais. Daí que, no campo educacional, especialmente no da gestão escolar, haja dificuldades em se implementar a gestão democrática, ainda mais diante da patente omissão dos sujeitos/atores da comunidade escolar, combinada ao franco declinar de suas obrigações e a subsequente transferência a quem os dirige.

Bordignon (2004) encontra a solução para o problema da participação e da cultura da participação no sentimento de pertença, baseado no 


\section{A. B. Stürmer; L. Soares Ferreira}

fato de que a participação se relaciona ao exercício do poder pela pessoa sobre o que lhe diz respeito subjetivamente: "Só há efetiva participação e compromisso quando se adquire a cultura do querer participar para exercer poder sobre o que lhe pertence, o que diz respeito à sua vida e ao seu futuro." (BORDIGNON, 2004, p. 307).

A não-participação aqui vem à tona como um problema, especialmente ao se recordar do tipo de relação que o indivíduo mantém com os bens públicos materiais - as escolas públicas - e imateriais - a educação e o ensino públicos. Basta verificar o cuidado dispensado pelos usuários aos prédios escolares, ao passeio público e a tudo o que é de uso coletivo; o mesmo se pode dizer do interesse da população com os rumos da educação pública e da participação da comunidade escolar na elaboração do PPP, por exemplo.

Muito embora a participação tenha um papel precípuo na formação para a cidadania e na consolidação da gestão democrática, os modos como ela se realiza, isto é, os "mecanismos de participação na gestão escolar" na expressão de Dourado (2003) -, não são de pouca relevância, já que integram um conjunto de espaços de formação e qualificação dos diversos membros da comunidade escolar e local, sem dizer que se constituem em um dos caminhos para novas formas de gestão da escola pública. Em outras palavras, os mecanismos de participação na escola garantem o caráter público da mesma e o atendimento à maioria da comunidade escolar.

O conselho escolar é um bom exemplo de mecanismo de participação, considerado por muitos o órgão máximo de direção (NUNES, 1999) ou órgão máximo de escola (AZEVEDO, 2007), o qual permite à participação não se vincular permanentemente à execução de tarefas. Pelo contrário, e inclusive, referir-se às decisões, para que não tenha um fim em si mesma, mas um meio para alcançar a democracia de alta intensidade (SANTOS, 2002) na gestão escolar. A essa altura, frente a avanços e recuos na luta por espaços de participação, há que se reconhecer a democracia representativa como um limite histórico e estabelecer a democracia participativa ou de alta intensidade como um princípio a ser perseguido e conquistado na escola.

\subsection{Espaços públicos de exercício da cidadania}

A formação para a cidadania, em curso nas escolas públicas, não pode se limitar à teoria, tal qual um tema transversal restrito ao mero dis- 
curso pedagógico, e sim voltar-se à prática, isto é, à participação democrática e cidadã. Assim, o "preparo para o exercício da cidadania" requer a ocupação de espaços públicos educativos já existentes no interior das escolas, mas subutilizados para essa finalidade, e que devem acolher toda a comunidade escolar: estudantes, pais e mães de estudantes, professores, funcionários, direção e apoio pedagógico.

As IGEDs, embora se constituam em espaços públicos de exercício da cidadania e construção permanente das instituições democráticas, geralmente deixam de ser utilizados para democratizar a gestão escolar. Deste modo, não contribuem para se alcançar uma democracia de alta intensidade, pois esta exige que todos os atores sociais envolvidos com a educação saibam reconhecer a instituição escolar - e suas IGEDs - como espaços públicos estruturados para a formação da cidadania em cada estudante.

Araújo (2002) entende que educar para a cidadania é elemento essencial para a democracia. Trata-se "da formação e instrução das pessoas para sua capacitação à participação motivada e competente na vida política e pública da sociedade". Uma formação que vise "ao desenvolvimento de competências para lidar com a diversidade e o conflito de ideias, com as influências da cultura e com os sentimentos e emoções presentes nas relações do sujeito consigo mesmo e com o mundo." (ARAÚJO, 2002, p. 3839)

Para muitas crianças, a escola tem sido o primeiro lugar público de socialização e interação com membros da sociedade que não fazem parte de seu convívio familiar ou comunitário; do que se conclui que a escola é um espaço privilegiado para a educação, a formação e o exercício legítimo da cidadania, ou seja, para que os estudantes aprendam a debater, negociar significados, tomar parte em decisões e exercer o direito à liberdade de expressão. Tudo sob orientação dos cidadãos-professores - aqueles que procuram formar estudantes que saibam de seus direitos, dentre eles o de participar.

A escola pública, vale lembrar, é uma instituição que se especializou, ao longo do tempo, na formação de cidadãos. Registra-se, em sua história, a preocupação com a adoração à bandeira, o canto do Hino Nacional e o estudo da Organização Social e Política do Brasil (OSPB). Hoje, contudo, formar para cidadania tomou outra conotação, mais atrelada ao incentivo da participação direta, do diálogo, do contato, enfim da ação comunicativa, em que os vários discursos sejam compreensíveis a todos. Para isso, reeditaram-se "velhas" formas colegiadas de funcionamento da escola bá- 


\section{A. B. Stürmer; L. Soares Ferreira}

sica, que atendessem a essas necessidades, ganhando uma roupagem nova.

Em 2006, o Ministério da Educação lançou o Programa de Fortalecimento dos Conselhos Escolares e, em 2008, a Secretaria de Estado da Educação, em SC, reeditou um manual de diretrizes para Entidades de Gestão Democrática Escolar (Conselho Deliberativo Escolar, Associação de Pais e Professores e Grêmio Estudantil). Isso demonstra o interesse dos governos em desenvolver a gestão escolar apoiada nesses órgãos colegiados, entidades de gestão democrática ou as aqui denominadas Instâncias de Gestão Escolar Democrática (IGEDs).

As duas principais tarefas das IGEDs dentro das escolas públicas são:

a) Levar a comunidade escolar e local a participar ati-
vamente, enquanto construção em conjunto, da ges-
tão escolar, dividindo poder - aproximando os diferen-
tes segmentos que a compõem - mesmo diante dos obs-
táculos à participação, como o preconceito e a intole-
rância entre pessoas portadoras de níveis diferentes
de escolaridade e de conhecimento sobre o funciona-
mento e organização da escola;
b) Disseminar entre a população a noção de que a esco-
la pública está aberta a quem queira se somar ao esfor-
ço educativo, com o qual a sociedade deve colaborar5.

Essas tarefas podem resultar em uma nova cultura institucional capaz de envolver a todos os membros da comunidade, inclusive capacitando-os, se necessário, para uma participação mais qualificada nas reuniões e debates nas IGEDs. No entanto, cabe ao corpo gestor e docente a iniciativa de pôr em funcionamento essas instâncias, colocando-as à disposição da comunidade escolar e local, em função dos objetivos de formação para a cidadania. Portanto, além de organizar as IGEDs, é preciso que se proceda às ações democratizantes no seio escolar a ponto de se ver compartilhada a gestão e, assim, a responsabilidade sobre os rumos da escola, consubstanciados na respectiva proposta político-pedagógica.

\section{$5 \cdot 50$ cidadãos-professores na escola}

O maior desafio à implementação de um modelo dinâmico de gestão, baseado na participação colegiada, é a integração dos professores às Instâncias de Gestão Escolar Democrática (IGEDs), fazendo cumprir as finalidades da Educação Básica e o objetivo do ensino fundamental - a formação básica do cidadão (BRASIL, 1996)6. Pela condição de servidores do ensino público, os professores devem compor as IGEDs, instruir-se acerca de suas 
respectivas funções e apresentá-las à comunidade escolar, fortalecendo o processo de mudança das concepções de gestão escolar vigentes.

Paro (2000) interpreta a participação dos professores nos colegiados como algo inerente à suas funções e que está mais ao seu alcance, diferentemente do que acontece com pais e mães de estudante:

\begin{abstract}
Para os servidores da escola, a participação em colegiados, por exemplo, pode-se dizer que faz parte das tarefas de seu trabalho, para o qual ele recebe um salário. Muito embora o exercício da representação nesses colegiados lhes seja facultativa, não é difícil integrá-la ao rol das demais atividades que eles desempenham no interior da instituição escolar. O mesmo não acontece com os pais e mães de aluno, que embora devam ter motivações outras para a participação, não tem como atribuições profissionais integrar um conselho de escola, por exemplo. (PARO, 2000, p. $120)$.
\end{abstract}

Pode-se até mesmo considerar que os professores são os profissionais melhor preparados para desenvolvimento do binômio democracia e participação. Conforme Paro (2006), os professores situam-se na condição de educadores por excelência da escola, encarregados, como o pessoal técnico-pedagógico; das atividades-fim da instituição escolar, o que os coloca não somente como formadores de cidadãos, mas, de maneira ampla, como produtores diretos da educação escolar. Por isso, "sua presença numa administração democrática da escola deve ser preponderante” (PARO, 2006, p. 163).

Por um lado, os professores mantêm contato frequente com estudantes, pais e funcionários, e sua participação nas IGEDs os habilita gerir espaços-tempos de construção em conjunto, nos quais acumulam experiência com o debate, a negociação de regras, as proposições e os acordos. Por outro, a Lei de Diretrizes e Bases da Educação fixa entre as finalidades da Educação Básica a formação comum para o exercício da cidadania, portanto obrigando o professor a capacitar-se para formar seus estudantes para a cidadania.

No plano prático, contudo, como os professores agem? Estariam motivados para o trabalho de educar para a cidadania, isto é, formar cidadãos com base na participação direta em modalidade colegiada? E que tipo de relação os professores, enquanto cidadãos, estabelecem com os mecanismos de participação presentes na escola? Demonstram interesse em participar? Que importância atribuem aos instrumentos de democratização da 
gestão construídos coletivamente, como o PPP? Qual seu real compromisso com a instituição da democracia nas escolas públicas catarinenses?

\section{Análises a partir dos resultados da pesquisa}

Mas há que tentar o diálogo quando a solidão é vício. Carlos Drummond de Andrade

Devido às atribuições inerentes ao cargo de professor, a este interessa, na condição de cidadãos-professores, distinguir nas "administrações" ou "direções" de escolas públicas a estrutura e organização das mesmas, aproveitando o que oferecem para desenvolver seu trabalho de formador de cidadãos. Deve, por exemplo, observar a forma como os sujeitos que fazem o dia a dia da escola percebem-na e participam de seus espaços públicos de formação para a cidadania - Instâncias de Gestão Escolar Democrática (IGEDs) -, a fim de verificar os verdadeiros os entraves à expansão da democracia cidadã na escola.

O questionamento realizado aos cidadãos-professores dentro de pesquisa de campo, especialmente a respeito das IGEDs, mostrou que pairam dúvidas quanto à função de cada instância de gestão colegiada, uma vez que grande parte dos professores envolvidos na pesquisa não descreveu nenhum tipo de função para qualquer dos órgãos de gestão mencionados no instrumento de pesquisa (Conselho Deliberativo, Associação de Pais e Professores, Grêmio Estudantil).

Entende-se aqui que o conhecimento das instâncias de gestão colegiada seja um requisito para a participação qualificada de seus integrantes - inicialmente dos cidadãos-professores e seus estudantes. Se isso não acontecer, confirmam-se as suspeitas de que muitos professores não compreendem a organização de sua própria escola, logo não podem avaliar a fundo a importância das IGEDs ou sequer intuir a possibilidade de convertêlas, se for o caso, em instâncias de gestão genuinamente democráticas.

Entretanto, a simples participação dos eidadãos-professores nessas instâncias lhe permitiria inferir a função de cada uma, bem como traria a ciência dos documentos que as regem, como os estatutos, projeto pedagógico escolar, etc. - o que não se verificou na pesquisa de campo. Por ora, observa-se, da fala dos professores questionados, que as IGEDs mais mencionadas - Conselho Deliberativo e Associação de Pais e Professores - não possuem atuações correspondentes à instância com maior poder decisório na escola e de instância mais representativa entre pais e professores, res-

REGAE, Santa Maria, v. 1, n. 2 jul./dez. 2009 
pectivamente, conforme se depreende a respeito.

Um professor apontou como função do Conselho Deliberativo "fiscalizar o cumprimento do calendário escolar", dando mostras do alcance do entendimento acerca das possibilidades que as IGEDs abrem para a democratização da gestão escolar. De outro lado, a Associação de Pais e Professores (APP) é, por estes, revelada como uma instância presa a velhas funções, como o financiamento da escola (o "caixa escolar") por meio de atividades e eventos comunitários visando à arrecadação. Por outras palavras, a APP é vista como uma instância com funções quase que exclusivamente administrativas: "Administrar e obter recursos financeiros para a escola" $(\mathrm{P} 1)_{7}$ ou "Arrecadar fundos para a escola" (P4) e "Arrecadar fundos e prestar serviço voluntário” ( $\left.\mathrm{P}_{5}\right)$.

Na mesma linha de pensamento, considera-se que a APP "Contribui com a administração e finanças da escola" ( $\left.\mathrm{P}_{7}\right)$, em uma visão reducionista da IGED responsável pela comunicação entre a escola e a comunidade local, através da qual se podem discutir muito mais os aspectos pedagógicos relativos à aprendizagem escolar e ação político-pedagógica que aspectos meramente administrativos da gestão.

Quanto ao Grêmio Estudantil, outra IGED bastante lembrada pelos professores, se faz ausente e/ou é malvisto em ambientes escolares autoritários administrativa e pedagogicamente; possui funções, segundo os professores, de representar os interesses dos estudantes. Tal instância, desde que contribua com o desenvolvimento da democracia e da participação discente na escola, equivale a um núcleo de formação para a cidadania. Essa característica, porém, precisa se consolidar no Grêmio Estudantil a partir do esforço dos cidadãos-professores, no sentido de produzir um ambiente educativo dentro dessa IGED por meio de uma orientação adequada aos objetivos do Projeto Político-Pedagógico da escola.

A indagação aos professores sobre sua participação em alguma das três IGEDs acima mencionadas, a maioria diz que não participa de nenhuma, enquanto alguns até se justificam afirmando sua descrença nos órgãos colegiados de gestão - as IGEDs: "Não conheço exatamente a função de cada órgão e também porque há muita manipulação de ideias nas decisões desses órgãos" $\left(\mathrm{P}_{3}\right)$. Os cidadãos-professores ainda dão indícios de certa falta de iniciativa: "Nunca fui convidada a participar" $\left(\mathrm{P}_{4}\right)$ [pela direção de escola]; e, de modo diverso: "Fui nomeada pela direção e professores" (P5).

Como geralmente acontece em ambientes onde não se pratica uma gestão democrática, a intervenção da direção em qualquer das IGEDs esva- 
zia-lhes o poder de que possam desfrutar no seio da comunidade escolar, transformando-se em verdadeiros apêndices da direção. Acabam, deste modo, por ficar descaracterizadas devido à falta de autonomia e, ao perderem sua identidade, correm o risco de enfrentarem dificuldades para compor um pequeno grupo e até mesmo ficarem desativadas, no caso do Grêmio Estudantil, em havendo hipertrofia da direção de escola.

Em analogia com a divisão de poderes no Estado Moderno, a escola geralmente tem, na direção de escola, o executivo; na APP e Grêmio Estudantil, o legislativo, e no Conselho Deliberativo, o Judiciário. Porém, ao se ter uma forma de gestão antidialógica e autoritária, a direção concentra o poder de decisão e legitima suas ações através do Conselho Deliberativo, cuja existência é obrigatória nas instituições educacionais, e, secundariamente, busca apoio na APP. As demais IGEDs tendem a se atrofiar, deixando, deste modo, de contribuir com o atendimento dos interesses da maioria da comunidade escolar - professores, estudantes, pais, apoio pedagógico ou membros da comunidade local.

Esperando-se verificar o nível de conhecimento dos professores a respeito das IGEDs, foi perguntado sobre o conhecimento acerca do estatuto de cada uma (Conselho Deliberativo, Associação de Pais e Professores e Grêmio Estudantil). A maioria declarou não participar de qualquer IGED, confirmando o pouco conhecimento dos respectivos estatutos, apesar de serem documentos que trazem a razão de ser de cada órgão, os princípios, a forma de atuação e os dispositivos reguladores do seu efetivo funcionamento.

Sem o domínio do conteúdo dos estatutos não se pode atuar de forma ativa dentro das IGEDs, fiscalizar eventuais irregularidades e muito menos propor mudanças de rumo nas políticas que os orientam ou mesmo qualquer alteração de suas funções dentro da escola. Por exemplo, tornar o Conselho Deliberativo mais independente das ações da direção da escola, a Associação de Pais e Professores uma instância mais próxima de discussões pedagógicas que administrativo-financeiras e transformar o Grêmio Estudantil naquela instância promotora não somente dos eventos estudantis, de lazer, e sim de ações que concorram para o cumprimento dos objetivos da Educação Básica, para o esclarecimento dos estudantes a propósito das diferentes profissões, estágios, bolsas de estudo, participação em manifestações culturais, ações afirmativas e em movimentos sociais em geral, além da necessária participação política como cidadão.

Entretanto, o estatuto da Associação de Pais e Professores figurou 
como o mais conhecido dentre as respostas dos professores, seguido dos estatutos do Conselho Deliberativo e Grêmio Estudantil, este que, por guiar a atuação de um segmento praticamente excluído da gestão escolar e não contar com significativo apoio dos professores foi pouco citado. Deduz-se que não haja um trabalho de divulgação dos estatutos de cada IGED, por parte da "administração" das escolas entre os professores, a fim de levar a conhecimento público os elementos que dão suporte à ação das IGEDs, que auxiliam na forma de gestão da escola, de sua organização e funcionamento.

Procurou-se saber, também, o tipo de relação do professor com os instrumentos de elaboração coletiva - complementares às ações das IGEDs - apropriados à democratização da gestão escolar e objeto de discussão permanente nas escolas e suas instâncias colegiadas. O Projeto PolíticoPedagógico (PPP), juntamente com o regimento escolar e os planos de curso, faz parte dos principais documentos que servem à construção de uma escola democrática, pois, desde sua concepção, exige a participação, o debate e o envolvimento de toda a comunidade escolar. Ao solicitar que os professores nomeassem um documento utilizado pela "administração" de sua escola da escola, o mais lembrado foi o Projeto Político-Pedagógico, seguido pelo regimento escolar e o estatuto do servidor. Destarte, ficaram demonstrados o status que o Projeto Político-Pedagógico goza no seio escolar e a presença desse documento possivelmente tem nas discussões pedagógico-administrativas escolares.

Sabendo-se de antemão que o PPP vem se fazendo presente na escola, perguntou-se sobre qual seria a relevância que os professores lhe atribuem. Como resposta, registrou-se que o mesmo é um documento que goza de alto grau de importância no cotidiano escolar, pois, segundo foi apontado, afeta "todas as decisões tomadas a nível escolar" (P1), "norteia as ações dentro da UE [Unidade Escolar]" $\left(\mathrm{P}_{5}\right)$ e, afinal, "orienta todas as atividades escolares" (P4). Logo, consta como "essencial para orientação e direcionamento do trabalho dos profissionais da escola" (P6), uma espécie de documento "vital" (P2), o qual conteria as leis gerais do funcionamento da escola. O PPP constitui-se em instrumento de compartilhamento de decisões na escola e elemento fundamental à construção de uma escola democrática e comprometida com a formação para a cidadania.

Os requisitos ou condições para que uma escola seja mais democrática aparecem claramente nas respostas dos professores: o encontro, a escuta, o respeito e a liberdade de opinião. Em outras palavras, solicita-se para 


\section{A. B. Stürmer; L. Soares Ferreira}

a escola uma participação dialógica. A análise das respostas impressiona: escancara-se a carência de espaços de diálogo, nos quais se possa falar e ser escutado, mesmo em se tratando de escolas públicas; pelo desejo de se aproximar de toda a comunidade escolar, realizando um trabalho coletivo; e pela reivindicação do poder de decidir.

Algumas falas colocam a descoberto um ambiente que mistura IGEDs ou "órgãos escolares" democráticos com nítidas restrições à liberdade de expressão, que, contraditoriamente, é o que se deseja ensinar nesse mesmo ambiente através de uma formação cidadã. Assim se manifestam os professores: “(...) não temos a liberdade de expressar nossas opiniões e participarmos de todos os órgãos escolares.” (P4); “(...) cada escola elabora seu PPP conforme sua população cultural [sic] e econômica, e esbarra sempre em uma lei maior, que não leva a [sic] aspirações de determinado grupo." (P6).

Conquanto a falta de liberdade individual e institucional (falta de autonomia escolar) seja apontada como fator inibidor do desenvolvimento de escolas democráticas, à pergunta "A Sra.(Sr.) considera o seu local de trabalho uma escola democrática?”, os professores demonstram pouca reflexão sobre as próprias atitudes - aquelas que o indivíduo, cidadãos-professores, poderiam tomar perante o problema da falta de liberdade na escola. Ao final das contas, contudo, revelam, por meio de suas tácitas reivindicações, a consciência de que para se prosseguir na construção de uma escola democrática não se pode dispensar o diálogo franco, a participação nas IGEDs e a valorização o PPP, que é o instrumento que condensa e consolida as negociações e os acordos firmados entre todos nos encontros promovidos pelas IGEDs.

Não é somente com a existência das IGEDs e do PPP, do diálogo e da autonomia escolar, que se garantirá uma escola democrática. Após auscultar as percepções dos professores sobre democracia na escola e ainda os critérios pessoais utilizados para definir uma escola como democrática (a presença do encontro, a escuta, o respeito, a liberdade de opinião), urge dirigir o olhar para as ações concretas. Por isso, perguntou-se qual seria o ponto de partida rumo à inserção no processo de democratização de sua escola. Respondendo sobre qual seria a primeira ação para democratizar sua escola, o professor, resumidamente, disse o seguinte: sabe que o caminho do diálogo lhe deve ser propiciado, que, se as imposições externas li- 
mitam a ação da escola, existem as IGEDs para que se estabeleça o debate a partir delas. Daí chega-se à conclusão de que é preciso buscar soluções internas, dentro da própria instituição.

Como já foi comentado, o professor-cidadão reconhece que a escola pública em que trabalha não é plenamente democrática, mas que é possível operar mudanças: então, não localiza onde está a força motriz e não participa ativamente das IGEDs, nem as reconhece como instâncias que constituem mais um lócus de ação para a cidadania.

Um termo recorrente nas entrevistas foi "abertura”. Em especial, "abertura" para que todos os segmentos possam expor suas opiniões e decidir pelo voto. Abertura também para a participação ativa dentro da comunidade escolar, que implica "Dar mais força de decisão aos professores" (P1), isto é, "Ouvir os professores para saber o que eles precisam para ministrar as aulas de forma ideal. Ouvir mais a todos." (P2). Portanto, veem-se novamente a reivindicar o diálogo, que corresponde, de uma só vez, à participação e à exposição de opiniões - bases sobre as quais se democratiza uma gestão escolar e através das quais se pode, destarte, construir uma escola democrática.

De modo mais contundente, ainda que singelo, a fala de uma professora exprime talvez seu desejo de participar como uma necessidade da comunidade escolar: "Possibilitar a participação das pessoas que fazem a escola." ( $\mathrm{P}_{3}$ ); anseio cujo exercício pareceria óbvio acontecer costumeiramente nas instituições públicas, porque fundamenta o convívio democrático no espaço escolar. Todavia, o caminho para tanto é "Criar mecanismos de participação e abertura da comunidade escolar.” (P4). Especificando um desses mecanismos, registrou-se: a "Escolha da direção por voto direto."

A intensidade do desejo de participação almejada serve de termômetro do grau de democratização alcançado na instituição escola. Quer dizer: quanto menos democrática escola, maior a preocupação dos cidadãos-professores com a participação incipiente por eles vivenciada. Sobre essa questão, um professor se referiu à presença e participação dos pais como o que é preciso para que sua escola seja mais democrática, embora se saiba que a participação dos pais, geralmente, configurar-se não como uma construção em conjunto, mas como simples colaboração ou decisão sobre assuntos corriqueiros. Diferente de uma gestão democrático-participativa, na qual a elaboração do PPP se dá em conjunto, fortalecendo e estimulando a construção de uma escola pública democrática na rede catarinense de en- 


\section{A. B. Stürmer; L. Soares Ferreira}

sino. Portanto, a participação deve ser bem exercida, de modo que o respectivo parâmetro seja a socialização do poder decisório com a maioria.

\section{Considerações finais}

Uma escola democrática testemunha a existência de uma gestão também democrática, apoiada nas Instâncias de Gestão Escolar Democrática (IGEDs), que são instrumentos fundamentais de democratização da escola - espaços públicos de formação e exercício da cidadania. O docente que se compromete com uma escola dessas dirige seu trabalho a uma das três grandes finalidades da Educação Básica previstas na Lei de Diretrizes e Bases da Educação Nacional (formação para a cidadania, para o mercado de trabalho e para estudos posteriores).

A construção de escolas democráticas depende do protagonismo dos cidadãos-professores, os quais precisam buscar desenvolver os mecanismos de participação na gestão escolar, tomar parte nas IGEDs, dando continuidade ao processo de democratização da própria sociedade. Ao utilizar o Conselho Deliberativo, Associação de Pais e Professores e o Grêmio Estudantil como instâncias de formação para a cidadania, auxilia na consolidação de experiências escolares segundo o paradigma da gestão, que é compatível com os objetivos primeiros das IGEDs: desenvolver relações democráticas no ambiente escolar, estabelecer ações comunicativas baseadas no diálogo e que requeiram o encontro dos diferentes discursos, quer convirjam ou não e, finalmente, o pronunciamento das vozes silenciadas.

A comunidade escolar como um todo deve, igualmente, incentivar a participação de todos nestas instâncias que, não obstante ficarem à parte do currículo formal, são imprescindíveis à qualificação social e política das comunidades escolares ligadas à Educação Básica e, como integrantes delas, os estudantes, pais e professores, que, formando os outros, formam-se a si próprios agentes da cidadania, dentro e fora da escola, conferindo a escola um destaque na formação cidadã.

Conclamando todos a dialogar, debater e negociar, através da participação direta nas IGEDs e demais mecanismos de integração/inclusão política, os cidadãos-professores contribuem de maneira imensurável e única para inserir sua escola no processo de democratização escolar. Não apenas no que tange ao acesso ao saber escolar (escolarização) e à permanência do estudante na escola, mas democratização escolar no sentido de abertura da escola pública, alterando suas relações sociais internas e per-

REGAE, Santa Maria, v. 1, n. 2 jul./dez. 2009 
mitindo a participação da comunidade nas decisões, ou seja, dividindo poder e as responsabilidades com relação à educação pública.

Em outras palavras, os cidadãos-professores, no contexto da construção de escolas democráticas, são peças fundamentais a sustentar os projetos de autonomia da escola, de consecução coletiva da proposta pedagógica desta e de, por meio de uma reavaliação da cultura escolar, nela inserir novas práticas, de acordo com os parâmetros democráticos.

\footnotetext{
Notas:

1 Freire (1983, p. 33-34) denomina sociedade fechada aquela em que o ponto de decisão está fora dela. Não tem opções, exceto a de receber ordens. Não decide: é uma 'sociedade-objeto', periférica, não-reflexiva. Ao invés de povo, tem massa. A sociedade fechada não é uma entidade participante, pois se estrutura de forma rígida e autoritária.

2 Pelo mesmo art. 53, inciso III, a criança e o adolescente têm o "direito de contestar critérios avaliativos, podendo recorrer às instâncias escolares superiores". 3 Lück (2006) classifica a participação em cinco formas: participação como presença; expressão verbal e discussão; representação política; tomada de decisão, e participação como engajamento.

4 A transformação do esquema de autoridade no interior da escola é posta por Paro (1997) como horizonte articulado aos interesses dos dominados e como o próprio processo pelo qual as camadas trabalhadoras conquistam a escola.

$5 \mathrm{O}$ art. 206 da Constituição Federal de 1988 coloca a família e o Estado no dever de educar e a sociedade na posição de colaboradora.

$6 \mathrm{LDB} / 96$, art. 32 .

7 As abreviações $\mathrm{P}_{1}, \mathrm{P}_{2}, \mathrm{P}_{3} \ldots$ significam, respectivamente, professor questionado $\mathrm{n}^{\circ} 1,2,3$ e assim por diante.
}

\section{Referências}

APP-SINDICATO dos Trabalhadores em Educação Pública do Paraná. A gestão democrática da educação e da escola. Caderno Pedagógico, Curitiba, PR, n. 4, p. 94-96, abr. 2007.

ARAÚJO, Ulisses. F. A constituição de escolas democráticas: histórias sobre complexidade, mudanças e resistências. São Paulo: Moderna, 2002.

AZEVEDO, José C. de. Os professores como inteligências

transformadoras na era da globalização. Caderno Pedagógico, Curitiba, n. 4 , p. $63-67$, abr. 2007.

BORDIGNON, Genuíno. Gestão democrática da escola cidadã. In: FRIGOTTO, Gaudêncio; CIAVATTA, Maria (orgs.). Ensino Médio: ciência, cultura e trabalho. Brasília: MEC/SEMTEC, 2004.

BRASIL. Constituição (1988). Constituição da República Federativa do Brasil. Brasília, DF; Senado Federal, 1988. Disponível em: <http:// 


\section{A. B. Stürmer; L. Soares Ferreira}

www.planalto.gov.br/ccivil_03/Constituicao/Constituiçao.htm>. Acesso em: 06 abr. 2009.

Lei no 8.069, de 13 de julho de 1990. Dispõe sobre o Estatuto da Criança e do Adolescente e dá outras providências. Diário Oficial [da] República Federativa do Brasil, Brasília, DF, 23 dez. 1996. Disponível em: <http:// www.planalto.gov.br/ccivil_03/Leis/L8069.htm>. Acesso em: 04 abr. 2009.

Lei no 9.394, de 20 de dezembro de 1996. Estabelece as diretrizes e bases da educação nacional. Diário Oficial [da] República Federativa do Brasil, Brasília, DF, 23 dez. 1996. Disponível em: <http://www.planalto.gov.br/ ccivil_03/Leis/L9394.htm>. Acesso em: 04 abr. 2009.

. Senado Federal. Parecer no 1.269, de 27 de agosto de 2008. Sobre o Projeto de Lei do Senado $n^{\circ} 344$, de 2007. Diário do Senado Federal, Brasília, DF, 12 dez. 2008. Disponível em: <http://www.senado.gov.br/sf/publicacoes/ diarios/pdf/sf/2008/12/11122008/51967.pdf>. Acesso em: 18 abr. 2009.

Senado Federal. Projeto de Lei do Senado $\mathbf{n}^{\mathbf{0}} \mathbf{3 4 4}$, de 14 de junho de 2007. Acrescenta o inciso III ao art. 14 da lei 9.394, de 20 de dezembro de 1996, de forma a instituir a eleição direta para diretores de escolas públicas. Diário do Senado Federal, Brasília, DF, 10 fev. 2009. Disponível em: <http:// legis.senado.gov.br/mate-pdf/10422.pdf >. Acesso em: 18 abr. 2009.

DOURADO, Luiz F. (org.). Gestão escolar democrática: a perspectiva dos dirigentes escolares da rede municipal de ensino de Goiânia-GO. Goiânia: Alternativa, 2003.

FREIRE, Paulo. Educação e mudança. 7. ed. Rio de Janeiro: Paz e Terra, 1983 .

GANDIN, Danilo. Escola e transformação social. 7. ed. Petrópolis: Vozes, 2001.

GUTIERREZ, Gustavo L.; CATANI, Afrânio M. Participação e gestão escolar: conceitos e potencialidades. In: FERREIRA, Naura S. C. (orgs.). Gestão democrática da educação: atuais tendências, novos desafios. 2. ed. São Paulo: Cortez, 2007. p. 59-75.

LÜCK, Heloísa. A gestão participativa na escola. Petrópolis, RJ: Vozes, 2006.

Gestão educacional: uma questão paradigmática. 3. ed. Petrópolis, RJ: Vozes, 2007.

. Perspectivas da gestão escolar e implicações quanto à formação de seus gestores. Em Aberto, Brasília, DF, v. 17, n. 72, p. 11-33, fev./jun. 2000.

MARQUES, Mário O. A formação do profissional da educação. 3. ed. Ijuí, 
RS: Unijuí, 2003.

NUNES, Andréa C. Gestão democrática ou compartilhada: uma (não) tão simples questão de semântica. Caderno Pedagógico, Curitiba, n. 2, p. 37-40, mar. 1999.

PARO, Vitor H. Administração escolar: introdução crítica. 14. ed. São Paulo: Cortez, 2006.

. Gestão democrática da escola pública. São Paulo: Ática, 1997.

2000.

Qualidade do ensino: a contribuição dos pais. São Paulo: Xamã,

SANTA CATARINA, Secretaria da Educação. Plano Estadual de Educação (1985-1988): democratização da educação - a opção dos catarinenses. 2. ed. Florianópolis: IOESC, 1985.

Secretaria de Estado da Educação. Lei Complementar no 170 , de o7 de agosto de 1998. Dispõe sobre o Sistema Estadual de Educação. Diário Oficial [do] Estado de Santa Catarina, Florianópolis, SC, 21 ago. 1998. Disponível em: <http://secon.udesc.br/leis/lei_170-1998.htm>. Acesso em: o3 abr. 2009 .

SANTOS, Boaventura de S. Quais os limites e possibilidades da cidadania planetária? In: FÓRUM SOCIAL MUNDIAL, 2., 2002, Porto Alegre. Anais eletrônicos... Porto Alegre: FSM, 2002. Disponível em: <http:// www.dhnet.org.br/w3/fsmrn/fsm2002/paineis/boaventura.html>. Acesso em: 17 abr. 2009 .

THIOLLENT, Michel. Metodologia da pesquisa-ação. 8. ed. São Paulo: Cortez, 1998.

\section{Arthur Breno Stürmer}

Autor. Especialista em Gestão Educacional. EEB. Benjamin Carvalho de Oliveira (Ipumirim/SC). Professor e Assistente Técnico-Pedagógico.

E-mail para correspondência:

arthur.sturmer@hotmail.com

\section{Liliana Soares Ferreira}

Orientadora. Doutora em Educação. Universidade Federal de Santa Maria.

Professora do Programa de Pós-Graduação em Educação.

E-mail para correspondência:

anaililferreira@yahoo.com.br 